\title{
Serious Fungal Infections in Thailand
}

DOI:

10.1007/s10096-017-2927-6

\section{Document Version}

Accepted author manuscript

Link to publication record in Manchester Research Explorer

\section{Citation for published version (APA):}

Chayakulkeere, M., \& Denning, D. (2017). Serious Fungal Infections in Thailand. European Journal of Clinical Microbiology and Infectious Diseases, 36(6), 931-935. https://doi.org/10.1007/s10096-017-2927-6

\section{Published in:}

European Journal of Clinical Microbiology and Infectious Diseases

\section{Citing this paper}

Please note that where the full-text provided on Manchester Research Explorer is the Author Accepted Manuscript or Proof version this may differ from the final Published version. If citing, it is advised that you check and use the publisher's definitive version.

\section{General rights}

Copyright and moral rights for the publications made accessible in the Research Explorer are retained by the authors and/or other copyright owners and it is a condition of accessing publications that users recognise and abide by the legal requirements associated with these rights.

\section{Takedown policy}

If you believe that this document breaches copyright please refer to the University of Manchester's Takedown Procedures [http://man.ac.uk/04Y6Bo] or contact uml.scholarlycommunications@manchester.ac.uk providing relevant details, so we can investigate your claim.

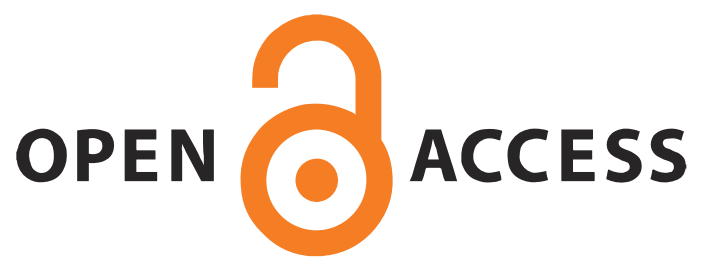


Original Article

2

3 Serious Fungal Infections in Thailand

4

$5 \quad$ Methee Chayakulkeeree ${ }^{1}$, David W. Denning ${ }^{2}$

$6{ }^{1}$ Division of Infectious Diseases and Tropical Medicine, Department of Medicine, Faculty of

7 Medicine Siriraj Hospital, Mahidol University, Bangkok, Thailand

$8{ }^{2}$ The National Aspergillosis Centre in association with the LIFE program at www.LIFE-

9 Worldwide.org, The University of Manchester, United Kingdom

10

11 Correspondence:

12 Methee Chayakulkeeree, MD, PhD, Division of Infectious Diseases and Tropical Medicine,

13 Department of Medicine, Faculty of Medicine, Siriraj Hospital, Mahidol University, Wanglang

14 Road, Bangkoknoi, Bangkok 10700, Thailand

15 Tel.: +6624199462

16 Email: methee.cha@mahidol.ac.th

17 


\section{Abstract}

The burden of serious fungal infection in Thailand is increasing but data regarding its incidence and prevalence are lacking. In this study we aimed to estimate the burden of serious fungal diseases in Thailand based on the size of the populations at risk and available epidemiological databases. Data derived from The Bureau of Epidemiology, Department of Disease Control, Thai Ministry of Public Health, World Health Organisation, international and local reports, and some unreported data were used. When no data existed, risk populations were used to estimate frequencies of fungal infections, using previously described methodology by LIFE. Recurrent vulvovaginal candidiasis (>4 episodes per year) is estimated to occur in 3310 per 100,000 population. Using a previously described rate that 14/10,000 admissions with fungaemia and 94\% being Candida, we estimated 8650 patients with candidaemia. The prevalence of chronic pulmonary aspergillosis is relatively high with a total of 19,044 , approximately half subsequent to pulmonary tuberculosis. Invasive aspergillosis is estimated to affect 941 patients following leukaemia therapy, transplantations, and chronic obstructive pulmonary disease, approximately 1.4/100,000. In addition, allergic bronchopulmonary aspergillosis and severe asthma with fungal sensitisation were estimated at approximately 58.4/100,000 and 77/100,000, respectively. Given approximately 8134 new cases of AIDS annually, cryptococcal meningitis, Pneumocystis pneumonia, and Talaromyces marneffei infection are estimated at 1.9/100,000, 2.6/100,000, and $0.3 / 100,000$, respectively. The present study indicates that about $1.93 \%(1,254,562)$ of the population is affected by serious fungal infections. Owing to the lack of data, reports, and statistics, the number of patients with mycoses in Thailand can only be estimated.

Keywords: Fungal diseases; Fungal infection; Burden; Epidemiology; Thailand 


\section{$57 \quad$ Methods}

58 The methodology of the LIFE program (www.LIFE-worldwide.org) was used to estimate the

59 burden of fungal diseases in Thailand with the model described previously [6]. We searched the

60 literature related to the epidemiology of invasive fungal diseases in Thailand using PubMed and 61 local journal databases. Where the information was not available, we calculated populations at 62 risk for each fungal infection and used these data to estimate the burden of each fungal infection. 63 Specific risk factors for acquirement of invasive fungal infections included HIV infection, use of 
64 immunosuppressive drugs, haematopoietic stem cell transplantation, solid organ transplantation, 65 chronic pulmonary diseases, and intensive care unit (ICU) admission. Population data and data related to HIV infection were derived from the Official Statistics

67 Registration System (http://stat.dopa.go.th; access 2014) and The Bureau of Epidemiology and 68 Department of Disease Control of the Thai Ministry of Public Health (www.ddc.moph.go.th; 69 access 2013), UNAIDS (www.unaids.org; access 2012), and the World Health Organisation 70 (www.who.int). Data related to transplant recipients were derived from the Thai Transplantation 71 Society (www.thai-transplant.org). Data gathered related to the period 2012 to 2014, depending 72 on availability. International and local reports were used to estimate each invasive fungal 73 disease. 


\section{Results and Discussion}

Thailand is classified as an upper middle income country by the World Bank (www.worldbank.org). The gross domestic product per capita in 2013 was $\$ 5,779$. During the study period, the population of Thailand was approximately $65,124,716,18 \%$ of whom were children under 15 years of age, $41 \%$ were adult women, and $14 \%$ were women over 50 years of age. According to the UNAIDS report, the total number of HIV-infected cases was 306,336, with 8134 new cases of acquired immune deficiency syndrome (AIDS) annually. Only 76\% of HIVinfected patients received ART. The total number of annual cases of tuberculosis was approximately 47,201 in both HIV-negative and HIV-positive individuals. Approximately 731,450 cases were diagnosed with chronic obstructive pulmonary disease (COPD), 51,202 of whom were admitted to hospital annually. The asthma rate in adults was 2.91 per 100,000, in about 1.5 million patients, whereas cystic fibrosis is extremely rare [7]. We estimated 911 patients with acute myeloid leukaemia (AML) based on the incidence rate of 1.5/100,000 in males and 1.3/100,000 in females [8]. According to the limited data available in 2013, about 150 patients received allogeneic haematopoietic stem cell transplantation (HSCT) [9], 465 renal transplantation, 7 lung transplantation, and 12 liver transplantation. However, the number of transplantation cases continues to increase.

The burden of fungal infections in Thailand is shown in Table 1, stratified by specific risk groups. Recurrent vulvovaginal candidiasis (RVVC) was defined as having at least four specific episodes of vulvovaginal candidiasis occur in one year or at least three episodes unrelated to antibiotic therapy within one year $[10,11]$. Given that data related to RVVC are not available in Thailand, we estimated according to previous studies that RVVC occurs in approximately $6 \%$ of adult women 15-50 years old [12]. Therefore, the prevalence of RVVC was about 1655/100,000, 
98 giving a total burden of 1,077,721 each year. However this number may be underestimated,

99 because many women with RVVC do not seek medical advice, preferring to take over-the100 counter drugs.

Candidaemia can occur in neutropenic and non-neutropenic hosts. Approximately $10 \%$ of

102 the total population, about 6.5 million people, are admitted to hospital each year. For non103 neutropenic patients, using a previously reported rate in a Thai publication that 14 out of 10,000 admissions had fungaemia and 94\% were Candida spp., we estimated 8561 non-neutropenic 105 patients with candidaemia annually [13]. Our local data revealed that about $4.5 \%$ of neutropenic 106 patients had candidaemia, producing an estimate of 89 cases per year. These data made up a total 107 burden of 8650 candidaemia cases per year. We estimated that approximately $20 \%$ of HIV108 infected individuals who received ART and 5\% of HIV-infected individuals who did not receive ART would have oesophageal candidiasis, producing a burden of oesophageal candidiasis of 45,396 cases $[14,15]$. We were unable to estimate oropharyngeal and oesophageal candidiasis in patients with other immunocompromised conditions because of the lack of data.

Data from The Department of Disease Control, Ministry of Public Health of Thailand reported that the number of new AIDS cases in 2013 amounted to 8134 . We estimated that $21 \%$ 114 of these presented with Pneumocystis pneumonia (PCP) [16]. Therefore, the total burden of PCP 115 was 1708 cases (2.6 per 100,000) annually. However, for PCP in steroid users or transplant 116 recipients we were not able to estimate its incidence due to unavailability of local data.

Thailand is an endemic for Talaromyces marneffei but the disease is prevalent in the northern part of Thailand, and Histoplasma capsulatum is found sporadically throughout the 119 country. Histoplasmosis and T. marneffei infection were estimated to occur in about $0.39 \%$ and 120 $2.26 \%$ of new AIDS cases, respectively. Therefore, the total burden of histoplasmosis and $T$. 
121 marneffei infection was 184 and 32 cases per year, respectively. However, these dimorphic 122 fungal infections also occur in non-HIV-infected patients but this requires active surveillance to 123 capture.

Among 306,336 AIDS cases, 232,816 were on ART (76\% coverage of those with a $\mathrm{CD}_{4}$

125 T-lymphocyte count $<350$ cells $/ \mathrm{mm}^{3}$ ); therefore, 73,520 individuals were not on treatment. If $12625 \%$ of these patients have a $\mathrm{CD}_{4} \mathrm{~T}$-lymphocyte count $<100$ cells $/ \mathrm{mm}^{3}, 18,380$ patients are at 127 risk for fungal infection. From seroprevalence studies in Thailand [17, 18], we estimated that 128 cryptococcosis occurred in about $13 \%$ of $\mathrm{HIV}$-infected individuals who had a $\mathrm{CD}_{4} \mathrm{~T}$-lymphocyte 129 count $<100$ cells $/ \mathrm{mm}^{3}$. Therefore, the incidence of cryptococcosis cases was 2389 annually, 130 assuming that all those on $\mathrm{ART}$ are not at risk and there is no risk for those with a $\mathrm{CD}_{4} \mathrm{~T}_{-}$ 131 lymphocyte count between 100 and 200 cells $/ \mathrm{mm}^{3}$. The number in HIV-infected patients has 132 decreased from the last decade because of the improved access to ART.

A previous study reported approximately 15 cryptococcal meningitis cases in non-HIV 134 patients per 100 HIV-infected patients with cryptococcal meningitis [19]. Therefore, the burden 135 of cryptococcal meningitis was calculated to be $4.2 / 100,000$, including an estimated 108 cases in 136 non-immunocompromised people (Table 1).

Owing to a relatively high incidence of pulmonary tuberculosis (TB) in Thailand (about 13847,201 cases annually), the estimated prevalence of chronic pulmonary aspergillosis (CPA) is 139 relatively high. We estimated that approximately $22 \%$ of pulmonary TB cases have cavitary 140 lesions and $22 \%$ of cavitary TB cases have CPA, whereas $2 \%$ of non-cavitary TB patients have 141 CPA [20]. Therefore, using the LIFE program, we estimated over 3000 new CPA cases annually 142 and a 5 year prevalence of 9,522 cases after pulmonary tuberculosis. Given a high rate of COPD, 143 numerous non-tuberculous mycobacterial infections and moderately large number of asthmatic 
144 patients, we estimated that tuberculosis comprises $50 \%$ of the total of CPA cases in Thailand.

145 Therefore we estimate the total to be about 19,044 CPA cases a year, approximately half 146 following TB.

147 Invasive aspergillosis (IA) is estimated to affect 941 patients following leukaemia 148 therapy, transplantation, and COPD, for a rate of $\sim 1.4 / 100,000$. We estimated these figures from 149 our local data estimation, assuming that IA occurred in approximately $13.5 \%$ of leukaemia 150 patients, 3\% of kidney transplant patients and $4 \%$ of lung and liver transplant patients [21, 22]. 151 Furthermore, IA was estimated to occur in $1.3 \%$ of COPD, which was less than reported from 152 Western countries [21].

153 Allergic bronchopulmonary aspergillosis (ABPA) is an uncommon, but significant 154 complication of asthma, almost always occurring in adulthood. Various studies put the 155 prevalence at about $2.5 \%$ of patients, including one from China [23]. We therefore estimated that 156 about 38,000 are affected, or 58.4/100,000 [24]. Severe asthma with fungal sensitisation (SAFS) 157 also responds to antifungal therapy and was estimated to occur in $33 \%$ of severe asthma, which 158 was about $10 \%$ of all asthma cases. Therefore, the burden of SAFS is thought to be about 50,000 159 adults $(77 / 100,000)$. There is probably some overlap or duplication between ABPA and SAFS as 160 sensitisation to A. fumigatus is universal in ABPA, common in SAFS, and many ABPA patients 161 have severe asthma, depending on the definition used.

In addition, owing to the lack of epidemiological data we could only assume a total of 163 about 130 cases of mucormycosis annually in Thailand. This rate is based on a simple and 164 conservative 2 per million estimate which is likely to be an underestimate. In one hospital, for 165 example, 11 patients were diagnosed and treated over five years at in Khon Kaen, a city with a 166 population of about 370,000 [25]. Numerous other reports attest to mucormycosis occurring in 
167 multiple locations in Thailand. This low estimate is in contrast to higher rates in India, where 168 diabetes is now very common, with a rate of $14 / 100,000$.

169 For fungal keratitis, we calculated from the available data in Thailand that infectious 170 keratitis occurs in about 1 per 1000 of population and $15 \%$ of infectious keratitis were caused by 171 fungi [26]. The burden of fungal keratitis was therefore $15 / 100,000$. This contrasts with rates in 172 other SE Asian countries substantially higher than this, notably Myanmar (710/100,000) [27] and 173 Nepal $(73 / 100,000)[28]$.

174 For tinea capitis, local data revealed about 16 cases per year at the National Children's 175 Hospital (with a total of 350,000 outpatient cases per year), so we estimated a burden of about 5 176 in 100,000 children. In a total paediatric population of $1,172,245$, the total number of tinea 177 capitis cases was 59 per year. In fact, this number is probably an underestimate because the data 178 we used to calculate this number are limited.

179 In conclusion, the present study indicates that approximately $1.93 \%(1,254,562)$ of the 180 population in Thailand is affected by serious fungal infections. Owing to the lack of data, reports, 181 and statistics, the number of patients with mycoses in Thailand can only be estimated. 
183

184 1. Hsu LY, Lee DG, Yeh SP, Bhurani D, Khanh BQ, Low CY, et al. (2015) Epidemiology 186 prospective observational study. Clin Microbiol Infect 21:594 e597-511

187 2. Faksri K, Kaewkes W, Chaicumpar K, Chaimanee P, Wongwajana S. (2014) 188 Epidemiology and identification of potential fungal pathogens causing invasive fungal infections 189 in a tertiary care hospital in northeast Thailand. Med Mycol 52:810-818

190 3. Chayakulkeeree M, Perfect JR. (2006) Cryptococcosis. Infect Dis Clin North Am 20:507$191544, \mathrm{v}-\mathrm{vi}$

192 4. Chayakulkeeree M, Vongwiwatana A. (2014) Invasive mold infection in kidney 193 transplant recipients: observation of early-onset mucormycosis. Transplant Proc 46:595-597

194 5. Apisarnthanarak A, Naknarongkij N, Kiratisin P, Mundy LM. (2009) Risk factors and 195 outcomes of Candida albicans and non-albicans Candida species at a Thai tertiary care center. 196 Am J Infect Control 37:781-782

197 6. Gamaletsou MN, Drogari-Apiranthitou M, Denning DW, Sipsas NV. (2016) An estimate 198 of the burden of serious fungal diseases in Greece. Eur J Clin Microbiol Infect Dis 35:1115-1120 199 7. Dejsomritrutai W, Nana A, Chierakul N, Tscheikuna J, Sompradeekul S, 200 Ruttanaumpawan P, et al. (2006) Prevalence of bronchial hyperresponsiveness and asthma in the 201 adult population in Thailand. Chest 129:602-609

202 8. Ekpunyasakul C. (2010) Epidemiology of adult leukemia: A descriptive study. Thai 203 Cancer Journal 30:77-83

2049 9. Issaragrisil S. (2008) Hematopoietic stem cell transplantation in Thailand. Bone Marrow 205 Transplant 42 Suppl 1:S137-S138 
206 10. Sobel JD. (2016) Recurrent vulvovaginal candidiasis. Am J Obstet Gynecol 214:15-21

207 11. Ringdahl EN. (2000) Treatment of recurrent vulvovaginal candidiasis. Am Fam Physician

$208 \quad 61: 3306-3312,3317$

209 12. Sobel JD. (2007) Vulvovaginal candidosis. Lancet 369:1961-1971

210 13. Anunnatsiri S, Chetchotisakd P, Mootsikapun P. (2009) Fungemia in non-HIV-infected

211 patients: a five-year review. Int J Infect Dis 13:90-96

212 14. Smith E, Orholm M. (1990) Trends and patterns of opportunistic diseases in Danish

213 AIDS patients 1980-1990. Scand J Infect Dis 22:665-672

214 15. Buchacz K, Baker RK, Palella FJ, Jr., Chmiel JS, Lichtenstein KA, Novak RM, et al. 215 (2010) AIDS-defining opportunistic illnesses in US patients, 1994-2007: a cohort study. AIDS $216 \quad 24: 1549-1559$

217 16. Jaijakul S, Saksirisampant W, Prownebon J, Yenthakam S, Mungthin M, Leelayoova S, 218 et al. (2005) Pneumocystis jiroveci in HIV/AIDS patients: detection by FTA filter paper together 219 with PCR in noninvasive induced sputum specimens. J Med Assoc Thai 88 Suppl 4:S294-299

220 17. Lindsley MD, Mekha N, Baggett HC, Surinthong Y, Autthateinchai R, Sawatwong P, et 221 al. (2011) Evaluation of a newly developed lateral flow immunoassay for the diagnosis of 222 cryptococcosis. Clin Infect Dis 53:321-325

223 18. Harris JR, Lindsley MD, Henchaichon S, Poonwan N, Naorat S, Prapasiri P, et al. (2012) 224 High prevalence of cryptococcal infection among HIV-infected patients hospitalized with 225 pneumonia in Thailand. Clin Infect Dis 54:e43-50

226 19. Chayakulkeeree M, Wangchinda P. (2014) Clinical characteristics and outcomes of 227 patients with cryptococcal meningoencephalitis in a resource-limited setting. J Med Assoc Thai 22897 Suppl 3:S26-34 
229 20. Denning DW, Pleuvry A, D.C. C. (2011) Global burden of chronic pulmonary 230 aspergillosis as a sequel to pulmonary tuberculosis. Bull World Health Organ 89:864-872

231 21. Lortholary O, Gangneux JP, Sitbon K, Lebeau B, de Monbrison F, Le Strat Y, et al. 232 (2011) Epidemiological trends in invasive aspergillosis in France: the SAIF network (2005233 2007). Clin Microbiol Infect 17:1882-1889

234 22. Perkhofer S, Lass-Florl C, Hell M, Russ G, Krause R, Honigl M, et al. (2010) The 235 Nationwide Austrian Aspergillus Registry: a prospective data collection on epidemiology, 236 therapy and outcome of invasive mould infections in immunocompromised and/or 237 immunosuppressed patients. Int J Antimicrob Agents 36:531-536

238 23. Ma YL, Zhang WB, Yu B, Chen YW, Mu S, Cui YL. (2011) [Prevalence of allergic 239 bronchopulmonary aspergillosis in Chinese patients with bronchial asthma]. Zhonghua Jie He He $240 \quad \mathrm{Hu}$ Xi Za Zhi 34:909-913

241 24. Denning DW, Pleuvry A, Cole DC. (2013) Global burden of allergic bronchopulmonary 242 aspergillosis with asthma and its complication chronic pulmonary aspergillosis in adults. Med 243 Mycol 51:361-370

244 25. Chetchotisakd P, Boonma P, Sookpranee M, Pairojkul C. (1991) Rhinocerebral 245 mucormycosis: a report of eleven cases. Southeast Asian J Trop Med Public Health 22:268-273

246 26. Hirunpat C, Masae N. (2005) Fungal keratitis in Songklanagarind Hospital. Songkla Med 247 J 23:429-434

248 27. World Health Organization, Regional Office for South-East Asia. (2004) Guidelines for 249 the management of corneal ulcer at primary, secondary and tertiary care health facilities in the 250 South-East Asia region. 
251 28. Khwakhali US, Denning DW. (2015) Burden of serious fungal infections in Nepal.

252 Mycoses 58 Suppl 5:45-50

253 
254 Table 1 Burden of fungal infections in Thailand

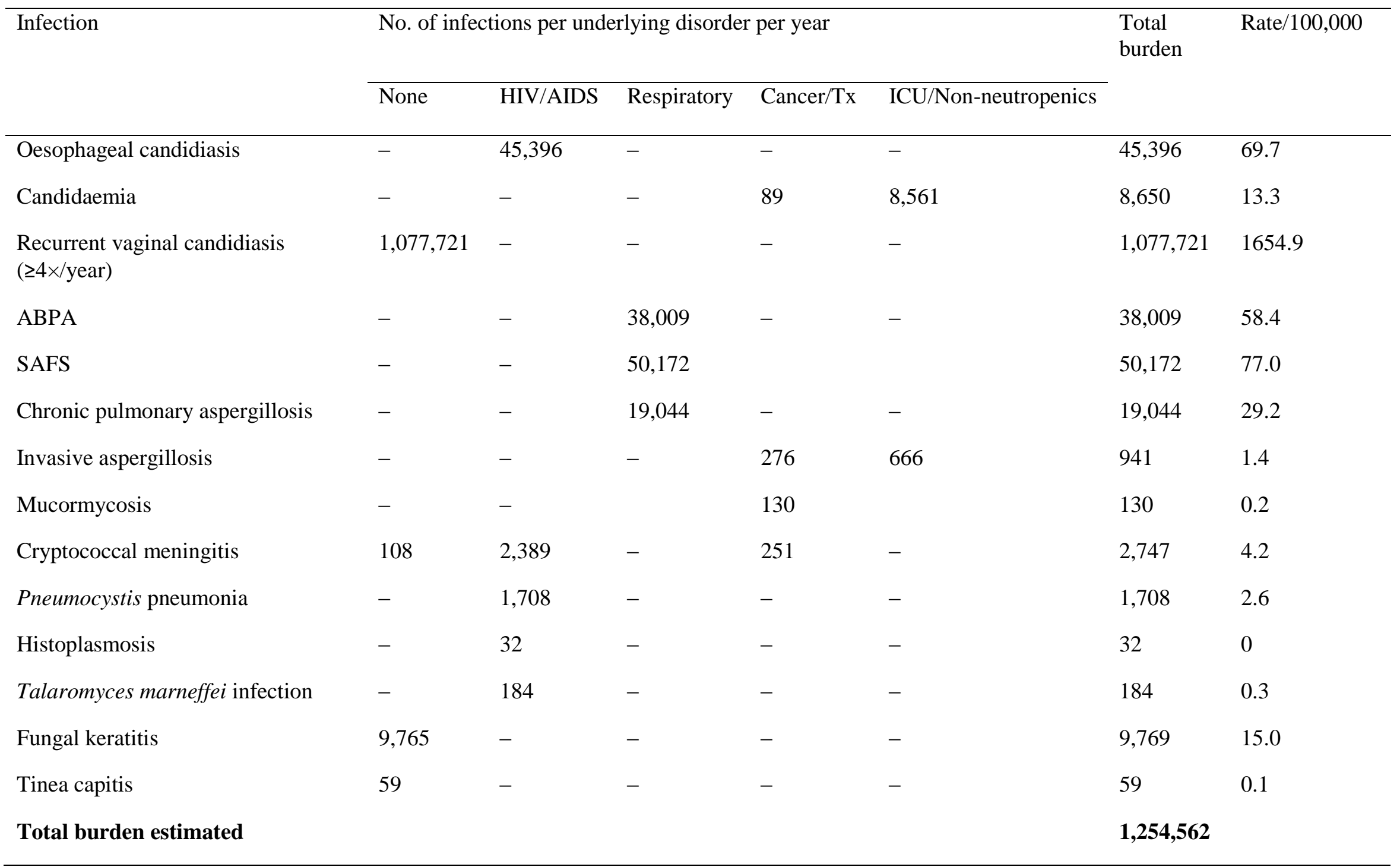


255 ABPA: allergic bronchopulmonary aspergillosis; AIDS: acquired immune deficiency syndrome; HIV: human immunodeficiency

256 virus; ICU: intensive care unit; SAFS: severe asthma with fungal sensitisation 